\title{
The analysis of the prognostic value of the neutrophil/ /lymphocyte ratio and the platelet/lymphocyte ratio among advanced endometrial cancer patients
}

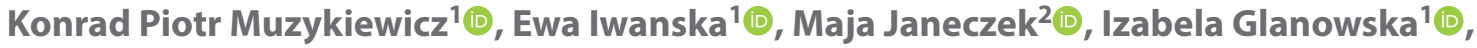 \\ Kazimierz Karolewski ${ }^{1}$, , Pawel Blecharz ${ }^{3}$ (D) \\ ${ }^{1}$ Department of Gynaecologic Oncology, Maria Sklodowska-Curie National Research Institute of Oncology, \\ Cracow Branch, Poland \\ ${ }^{2}$ Department of Gynaecology and Obstetrics, Stefan Zeromski Memorial Specialist City Hospital, Cracow, Poland \\ ${ }^{3}$ St. John's Cancer Centre in Lublin, Poland
}

\begin{abstract}
Objectives: About $20 \%$ of endometrial cancer (EC) patients have advanced disease (FIGO III \& IV) at the moment of diagnosis. An attempt to evaluate the prognostic value of biochemical markers of inflammation and classic endometrial cancer prognostic factors in the group of advanced $\mathrm{EC}(\mathrm{aEC})$ patients has been made in this study.

Material and methods: Records of 266 patients treated in the Maria Sklodowska-Curie Memorial Cancer Centre and Institute of Oncology, Cracow Branch between the year 2006 and 2018 were included in the study. Follow-up ranged from 1 to 138 months. Progression free survival (PFS) and overall survival (OS) have been set as endpoints. Tests such as: chi-squared, Fisher, log-rank, Mann-Whitney, Kruskal-Wallis and Cox proportional hazard ratio were used in the statistical analyses.

Results: In the analysed group high total platelet count (PLT) before operative treatment and high levels of white blood cells (WBC), PLT, neutrophil/lymphocyte ratio (NLR) and platelet/lymphocyte ratio (PLR) before adjuvant therapy (AT) have been significantly associated with shorter PFS and OS. After setting the cut-off values of NLR and PLR a statistically significant correlation between those parameters and PFS as well as OS has been shown. Multivariate analysis has indicated that NLR is an independent prognostic factor of the course of aEC.

Conclusions: NLR and PLR correlate significantly with OS and PFS in aEC. NLR is an independent prognostic factor in this group. It is possible to distinguish 3 risk groups, among aEC patients, based on NRL and PLR.
\end{abstract}

Key words: advanced endometrial cancer; NLR; PLR; adjuvant treatment

Ginekologia Polska 2021; 92, 1: 16-23

\section{INTRODUCTION}

Endometrial cancer (EC) is the most frequently diagnosed gynaecological malignancy in the developed countries. There is an upturn in morbidity especially among older women, in which group the treatment is the most difficult. Even though most endometrial cancer patients are diagnosed at an early stage of the disease, in 2016 in Poland 19\% of the reported cases were advanced endometrial cancer (aEC) [1-3]. Advanced endometrial cancer patients require an individual approach on every stage of treatment. Due to healthcare system setup in Poland many aEC patients begin their treatment in district hospitals and are referred to cancer centres after surgery. The amount of information available from before treatment is in most cases scarce. In this setting any data of reliable prognostic significance, that can be obtained while planning adjuvant treatment is very valuable.

The link between inflammation and carcinogenesis has been first described in the second half of $19^{\text {th }}$ century. Currently two pathways connecting carcinogenesis with the immune system are distinguished: extrinsic, where chronic inflammation creates an environment favourable to carcinogenesis and intrinsic, where cancer cells induce immunologic response favouring further development of the tumour [4-7]. The exact mechanisms underlying the interaction between coagulation, inflammation and carcinogenesis remain unclear. Neutrophils inhibit the immune system by suppressing T-type lymphocytes, and through secretion of various cytokines, chemokines and growth factors they take part in the creation of tumour inducing microenvironment. It is said that 
glycoproteins such as platelet-derived growth factor (PIGF), transforming growth factor beta (TGF- $\beta$ ) or vasculo-epithelial growth factor (VEGF) secreted by platelets play a similar role. This effect is amplified by increased platelet production and aggregation associated with cancer [8-11].

Among other markers derived from complete blood count $(C B C)$, the predictive value of neutrophil/lymphocyte ratio (NLR) and platelet/lymphocyte ratio (PLR) has been assessed for many types of tumours, such as breast, stomach, colon or lung cancer. There is paucity of data on its significance in endometrial cancer. [12-15]. At present there are no papers on their prognostic value in advanced endometrial cancer.

\section{Objectives}

The aim of this study was to assess the prognostic value of NLR and PLR calculated at the stage AT planning in aEC patients and the potential utility of these markers in clinical practice.

\section{MATERIAL AND METHODS}

Records of 266 patients treated in the Maria Sklodowska-Curie Memorial Cancer Centre and Institute of Oncology, Cracow Branch between year 2006 and 2018 were included in the analysis. Follow-up ranged from 1 to 138 months. Data collection was finished five years after the treatment of the last patient included in the study had ended. Detailed analysis of known EC prognostic factors, comorbidity, biochemical test results, type of surgery, its duration, extent and the hospital where it was performed, stage and grade of cancer, its histology and Bokhman type, the type of adjuvant treatment, and its outcome in RECIST criteria was performed.

Progression free survival (PFS) and overall survival (OS) have been set as endpoints and assessed in periods of 12 , 36 and 60 months. The patients have not been differentiated by the cause of death due to insufficient data.

Qualitative data was analysed by counting the number and percentage of each value. Comparison of those variables was made using chi-squared test or Fisher detailed test in case of groups with low expected quantity. Kaplan-Meier curves were used to demonstrate the results of the analyses of qualitative features, and their comparison was made using log-rank test. Quantitative data was analysed by counting the mean value, standard deviation, the median, quartiles, the minimal value and the maximal value. Comparison of those variables was made using Mann-Whitney test. In cases of three or more groups the comparison was made using Kruskal-Wallis test. Features which showed statistically significant differences were analysed post-hoc with Dunn test. Cox proportional hazard ratio model was used to examine the influence of quantitative features on PFS and OS. The results have been shown using hazard ratio (HR) with 95\% confidence interval. The cut-off values for tests based on quantitative data were determined using receiver operating characteristic (ROC) curves. Utility of a quantitative variable as a predictor was assessed using the area under the ROC curve (AUC). P value below 0.05 was set as the level of statistical significance. The analyses were made using $\mathrm{R}$ software.

\section{RESULTS}

The study group was comprised of 266 advanced endometrial cancer patients. The youngest patient was 34 , while the oldest was 91 years old at the time of the beginning of treatment. The average age was 65.5 , and its median was 66 years. 192 (72\%) of patients had comorbidity, of which the most common was arterial hypertension (169 cases $-63.5 \%)$. Furthermore, there were cases of ischemic heart disease, arrhythmia, diabetes mellitus, hypo- and hyperthyroidism, asthma, chronic obturatory pulmonary disease, vascular lesions, thromboembolism and other. One hundred thirteen patients were obese and further 72 were overweight. FIGO stage IIIB accounted for $35 \%$ of cases, followed by IIIA $-28 \%$ and IIIC $-24 \%$. Only $5 \%$ of patients were stage IV. There were 182 Bokhman type I EC cases, of which 152 were of pure endometrioid histology, and the others had mucinous and planoepithelial components. Bokhman type II EC cases accounted for $26 \%(n=70)$ of the group and were comprised of histological types such as: serous $(n=17)$, clear cell $(n=10)$, carcinosarcoma $(n=13)$ and mixed $(n=30)$. The detailed data is shown in Table 1.

Five-year overall survival rate in the study group was $49,6 \%$, and progression-free survival rate $45,4 \%$. Median OS was 60 months, while half of the patients had progression after 50 months. Table 2 shows detailed data.

There was paucity of data on detailed $\mathrm{CBC}$ before treatment, because in most treatment centres the neutrophil count and the lymphocyte count were not assessed before surgery. The CBC data collected before adjuvant treatment was far more complete and of better quality because most of the results came from a single laboratory in COOK. Survival analysis in the context of variables such as: age at the moment of diagnosis, BMI before treatment, WBC before surgery, and before adjuvant treatment (AT), PLT before surgery and before AT, NLR and PLR before AT, comorbidity, in particular DM and its treatment with metformin, FIGO stage, histologic grade, Bokhman type, depth of myometrial invasion has been performed. Results of the analysis for the variables which correlated significantly with PFS and/or OS are given in Table 3 and 4.

Afterwards ROC curves have been drawn for NLR and PLR. Area under curve (AUC) values were 0.608 for NLR and 0,613 for PLR (Fig. 1). Optimal cut-off values for examined parameters have been assessed, equalling:

- NLR $=3.88$ - sensitivity $80.6 \%$ and specificity $42.39 \%$

- PLR $=231.3$ - sensitivity $80.6 \%$ and specificity $42.39 \%$. 
Table 1. Demographic and clinical characteristic of the study group

Demographic and clinical characteristic of the study group

\begin{tabular}{|c|c|c|c|}
\hline Feature & Mean (SD) & \multicolumn{2}{|c|}{ Median (quartile) } \\
\hline \multirow{5}{*}{ Age [years] } & $65.47(9.75)$ & \multicolumn{2}{|c|}{$66(59-73)$} \\
\hline & & $\mathrm{N}$ & $\%$ \\
\hline & $22-44$ & 5 & 1.9 \\
\hline & $45-64$ & 112 & 42.1 \\
\hline & $65+$ & 149 & 56 \\
\hline \multirow{6}{*}{ BMI } & $30.13(5.93)$ & \multicolumn{2}{|c|}{$29.8(25.98-33.85)$} \\
\hline & Underweight $(<18.5)$ & 1 & 0.4 \\
\hline & Normal (18.5-25) & 44 & 16.5 \\
\hline & Overweight (25-30) & 72 & 27.1 \\
\hline & Obese $(>30)$ & 113 & 42.5 \\
\hline & No data & 36 & 13.5 \\
\hline \multirow{3}{*}{ Comorbidity } & Total & 192 & 72.18 \\
\hline & Hypertension & 169 & 63.53 \\
\hline & Diabetes mellitus & 58 & 21.8 \\
\hline \multirow{3}{*}{$\begin{array}{l}\text { Diabetic patients } \\
\text { treated with } \\
\text { metformin }\end{array}$} & Yes & 33 & 56.90 \\
\hline & No & 24 & 41.38 \\
\hline & No data & 1 & 1.72 \\
\hline \multirow{6}{*}{ FIGO 2009 stage } & IIIA & 75 & 28.2 \\
\hline & IIIB & 93 & 34.96 \\
\hline & IIIC & 63 & 23.68 \\
\hline & IVA & 5 & 1.88 \\
\hline & IVB & 8 & 3.01 \\
\hline & No data & 22 & 8.27 \\
\hline \multirow{3}{*}{ Bokhman type } & Type I & 182 & 68.42 \\
\hline & Type II & 70 & 26.32 \\
\hline & No data & 14 & 5.26 \\
\hline \multirow{4}{*}{ Histological Grade } & G1 & 34 & 12.78 \\
\hline & G2 & 126 & 47.37 \\
\hline & G3 & 57 & 21.43 \\
\hline & No data & 49 & 18.42 \\
\hline
\end{tabular}

SD — standard deviation; BMI — body mass index
The results of a univariate analysis of the relation between dichotomised NLR and PLR values (high - above cut-off, low - below cut-off) and OS and PFS are given in Table 5, and on Figure 2 and 3 for NLR and PLR respectively. Due to the fact that both parameters presented statistically significant correlation with OS and PFS an attempt to distinguish three risk groups based on their value has been made: $\mathrm{LL}$ - both values "low", $\mathrm{HH}$ - both values "high", LH - one value "low" and the other one "high". The survival analysis in relation to subgroups has shown a significant correlation with both OS and PFS. Above-mentioned results are included in table 5 and presented on Figure 4.

A multivariate analysis of the prognostic value of NLR and PLR before AT was then conducted with inclusion of known significant prognostic factors such as age, histologic grade and Bokhman type. Due to similarity of NRL and PLR two separate analyses were done for each parameter alone. The results have shown that NRL was the only independent prognostic factor for both 5-year OS and PFS in the study group. Hazard ratios were similar for death and progression and equalled 2.6 in case of high NRL value. Detailed results of this analysis are presented in Table 6.

\section{DISCUSSION}

Neutrophils secrete an abundance of cytokines, growth factors and enzymes such as II-6, II-8, VEGF, HGF, metalproteinases and elastases, which take part in the creation of a tumour promoting microenvironment, by decomposition of the extracellular matrix, promotion of neoangiogenesis or inhibition of anti-cancer immune response - suppression of activated T-lymphocytes and natural killers. On the other hand, lymphocyte invasion into cancer tissue is frequently linked with better response to chemotherapy and thus better prognosis. NLR joins the neutrophil and the lymphocyte count into one clear parameter [16-19].

\begin{tabular}{|c|c|c|c|c|c|c|c|}
\hline \multirow{2}{*}{\multicolumn{2}{|c|}{ Number of patients }} & \multirow{2}{*}{\multicolumn{2}{|c|}{ Number of events }} & \multicolumn{4}{|c|}{ Overall survival } \\
\hline & & & & 12 months & 36 months & 60 months & Median [months] \\
\hline \multicolumn{2}{|c|}{266} & \multicolumn{2}{|l|}{106} & $87.23 \%$ & $59.54 \%$ & $49.59 \%$ & 60 \\
\hline \multirow{2}{*}{\multicolumn{2}{|c|}{ Number of patients }} & \multirow{2}{*}{\multicolumn{2}{|c|}{ Number of events }} & \multicolumn{4}{|c|}{ Progression-free survival } \\
\hline & & & & 12 months & 36 months & 60 months & Median [months] \\
\hline 266 & & 122 & & $71.02 \%$ & $53.14 \%$ & $45.42 \%$ & 50 \\
\hline \multicolumn{8}{|c|}{ Post-treatment follow-up [months] } \\
\hline $\mathrm{N}$ & Mean & SD & Median & Min & Max & Q1 & Q3 \\
\hline 266 & 36.94 & 31.63 & 25 & 1 & 138 & 11 & 61 \\
\hline
\end{tabular}

SD - standard deviation 
Table 3. Results of the analysis of selected variables in relation to overall survival

Results of the analysis of selected variables in relation to $0 \mathrm{~S}$

\begin{tabular}{|c|c|c|c|c|c|c|c|c|}
\hline $\mathbf{N}$ & \multicolumn{3}{|c|}{ Variable } & Unit & HR & $95 \% \mathrm{Cl}$ & & $\mathbf{p}$ \\
\hline 1 & \multicolumn{3}{|c|}{ Age at the moment of diagnosis } & years & 1.035 & 1.013 & 1.056 & 0.001 \\
\hline 2 & \multicolumn{3}{|c|}{ PLT before surgery } & $10^{3} / \mu \mathrm{L}$ & 1.003 & 1 & 1.005 & 0.02 \\
\hline 3 & \multicolumn{3}{|c|}{ WBC before AT } & $10^{3} / \mu \mathrm{L}$ & 1.073 & 1.046 & 1.101 & $<0.001$ \\
\hline 4 & \multicolumn{3}{|c|}{ PLT before AT } & $10^{3} / \mu \mathrm{L}$ & 1.005 & 1.003 & 1.006 & $<0.001$ \\
\hline 5 & \multicolumn{3}{|c|}{ NLR } & & 1.06 & 1.034 & 1.086 & $<0.001$ \\
\hline 6 & \multicolumn{3}{|c|}{ PLR } & & 1.001 & 1 & 1.002 & 0.011 \\
\hline \multirow{2}{*}{\multicolumn{2}{|c|}{ Variable }} & \multirow{2}{*}{$\begin{array}{l}\text { Number of } \\
\text { patients }\end{array}$} & \multirow{2}{*}{$\begin{array}{l}\text { Number of } \\
\text { deaths }\end{array}$} & \multicolumn{4}{|c|}{ Overall survival } & \multirow{2}{*}{$\mathbf{p}$} \\
\hline & & & & 12 months & 36 months & 60 months & Median [months] & \\
\hline \multicolumn{9}{|c|}{ 7. Histologic grade } \\
\hline & G1 & 34 & 8 & $93.21 \%$ & $77.03 \%$ & $64.19 \%$ & $>$ max obs. & \multirow{3}{*}{$\mathrm{p}<0.001$} \\
\hline & $\mathrm{G} 2$ & 127 & 40 & $92.22 \%$ & $71.65 \%$ & $63.24 \%$ & 116 & \\
\hline & G3 & 57 & 30 & $81.03 \%$ & $37.82 \%$ & $24.82 \%$ & 25 & \\
\hline \multicolumn{9}{|c|}{ 8. Bokhman type } \\
\hline & I & 183 & 57 & $91.32 \%$ & $69.08 \%$ & $59.83 \%$ & 116 & \multirow{2}{*}{$p<0.001$} \\
\hline & $\|$ & 71 & 42 & $75.24 \%$ & $40.53 \%$ & $28.43 \%$ & 25 & \\
\hline
\end{tabular}

OS - overall survival; $\mathrm{HR}$ - hazard ratio; $\mathrm{Cl}$ — confidence interval; PLT — total platelet count; WBC — white blood count; AT — adjuvant therapy; $\mathrm{NLR}$ - neutrophil/lymphocyte ratio; PLR — platelet/lymphocyte ratio

Table 4. Results of the analysis of selected variables in relation to progression free survival Results of the analysis of selected variables in relation to PFS

\begin{tabular}{|c|c|c|c|c|c|c|c|c|}
\hline $\mathbf{N}$ & \multicolumn{3}{|c|}{ Variable } & Unit & HR & $95 \% \mathrm{Cl}$ & & $\mathbf{p}$ \\
\hline 1 & \multicolumn{3}{|c|}{ Age at the moment of diagnosis } & [years] & 1.026 & 1.006 & 1.046 & 0.009 \\
\hline 2 & \multicolumn{3}{|c|}{ PLT before surgery } & $10^{3} / \mu \mathrm{L}$ & 1.003 & 1 & 1.005 & 0.027 \\
\hline 3 & \multicolumn{3}{|c|}{ LEU before AT } & $10^{3} / \mu \mathrm{L}$ & 1.064 & 1.043 & 1.085 & $<0.001$ \\
\hline 4 & \multicolumn{3}{|c|}{ PLT before AT } & $10^{3} / \mu \mathrm{L}$ & 1.004 & 1.003 & 1.005 & $<0.001$ \\
\hline 5 & \multicolumn{3}{|l|}{ NLR } & & 1.054 & 1.03 & 1.078 & $<0.001$ \\
\hline 6 & \multicolumn{3}{|l|}{ PLR } & & 1.001 & 1 & 1.002 & 0.036 \\
\hline \multirow{2}{*}{\multicolumn{2}{|c|}{ Variable }} & \multirow{2}{*}{$\begin{array}{l}\text { Number of } \\
\text { patients }\end{array}$} & \multirow{2}{*}{$\begin{array}{l}\text { Number of } \\
\text { events }\end{array}$} & \multicolumn{4}{|c|}{ Overall survival } & \multirow{2}{*}{$\mathbf{p}$} \\
\hline & & & & 12 months & 36 months & 60 months & Median [months] & \\
\hline \multicolumn{9}{|c|}{ 7. Histologic grade } \\
\hline & G1 & 34 & 10 & $80.40 \%$ & $73.09 \%$ & $63.34 \%$ & $>$ max obs. & \multirow{3}{*}{$p<0.001$} \\
\hline & $\mathrm{G} 2$ & 127 & 47 & $82.92 \%$ & $65.18 \%$ & $57.61 \%$ & 93 & \\
\hline & G3I & 57 & 34 & $52.86 \%$ & $27.11 \%$ & $23.24 \%$ & 15 & \\
\hline \multicolumn{9}{|c|}{ 8. Bokhman type } \\
\hline & I & 183 & 68 & $80.24 \%$ & $62.69 \%$ & $55.13 \%$ & 93 & \multirow{2}{*}{$\mathrm{p}<0.001$} \\
\hline & $\|$ & 71 & 46 & $48.74 \%$ & $32.63 \%$ & $24.16 \%$ & 12 & \\
\hline \multicolumn{9}{|c|}{ 9. Depth of myometrial invasion } \\
\hline & $<1 / 2$ & 39 & 10 & $88.89 \%$ & $75.00 \%$ & $71.43 \%$ & $>$ max obs. & \multirow{2}{*}{$p=0.018$} \\
\hline & $>1 / 2$ & 163 & 69 & $80.54 \%$ & $58.59 \%$ & $47.84 \%$ & 58 & \\
\hline
\end{tabular}

PFS — progression free survival; $\mathrm{HR}$ — hazard ratio; $\mathrm{Cl}$ — confidence interval; PLT — total platelet count; WBC — white blood count; AT — adjuvant therapy; NLR - neutrophil/lymphocyte ratio; PLR - platelet/lymphocyte ratio

A meta-analysis conducted by Templeton gives an overview of the results of 100 papers, which include 40,559 patients with solid tumours, to assess the prognostic value of
NLR [20]. Diseases such as breast, colon, ovarian, cervical cancer or mesothelioma were included, among others. There were no cases of endometrial cancer in the analysis. Cut-off 
Table 5. Prognostic value analysis of neutrophil/lymphocyte ratio and platelet/lymphocyte ratio as qualitative variables in relation to overall survival and progression free survival

\begin{tabular}{|c|c|c|c|c|c|c|c|}
\hline \multicolumn{8}{|c|}{ Prognostic value analysis of NLR and PLR as qualitative variables in relation to OS (1-3) and PFS (4-6) } \\
\hline \multirow{2}{*}{ Variable } & \multirow{2}{*}{$\begin{array}{l}\text { Number of } \\
\text { patients }\end{array}$} & \multirow{2}{*}{$\begin{array}{l}\text { Number of deaths } \\
\text { or events }\end{array}$} & \multicolumn{4}{|c|}{ Overall survival } & \multirow{2}{*}{$\mathbf{p}$} \\
\hline & & & 12 months & 36 months & 60 months & Median [months] & \\
\hline \multicolumn{8}{|c|}{ 1. NLR low (L) / high $(\mathrm{H})$ - OS } \\
\hline L & 155 & 58 & $89.53 \%$ & $64.98 \%$ & $56.67 \%$ & 116 & \multirow{2}{*}{$p=0.005$} \\
\hline H & 83 & 39 & $83.04 \%$ & $48.29 \%$ & $36.35 \%$ & 35 & \\
\hline \multicolumn{8}{|c|}{ 2. PLR low $(\mathrm{L}) /$ high $(\mathrm{H})-\mathrm{OS}$} \\
\hline $\mathrm{L}$ & 158 & 57 & $89.66 \%$ & $65.96 \%$ & $57.37 \%$ & 116 & \multirow{2}{*}{$p=0.001$} \\
\hline $\mathrm{H}$ & 80 & 40 & $82.67 \%$ & $46.12 \%$ & $35.37 \%$ & 28 & \\
\hline \multicolumn{8}{|c|}{ 3. Groups NLR + PLR - OS } \\
\hline LL & 135 & 48 & $90.39 \%$ & $67.46 \%$ & $58.87 \%$ & 116 & \multirow{3}{*}{$p=0.002$} \\
\hline $\mathrm{LH} / \mathrm{HL}$ & 43 & 19 & $84.44 \%$ & $52.06 \%$ & $44.86 \%$ & 42 & \\
\hline $\mathrm{HH}$ & 60 & 30 & $82.26 \%$ & $45.55 \%$ & $32.57 \%$ & 26 & \\
\hline \multicolumn{8}{|c|}{ 4. NLR low (L)/high (H) - PFS } \\
\hline L & 155 & 69 & $76.93 \%$ & $58.58 \%$ & $50.16 \%$ & 63 & \multirow{2}{*}{$p=0.008$} \\
\hline $\mathrm{H}$ & 83 & 44 & $54.06 \%$ & $41.26 \%$ & $36.25 \%$ & 18 & \\
\hline \multicolumn{8}{|c|}{ 5. PLR low (L) / high (H) - PFS } \\
\hline L & 158 & 69 & $74.63 \%$ & $60.40 \%$ & $50.90 \%$ & 63 & \multirow{2}{*}{$p=0.006$} \\
\hline H & 80 & 44 & $58.17 \%$ & $35.90 \%$ & $33.66 \%$ & 21 & \\
\hline \multicolumn{8}{|c|}{ 6. Groups NLR + PLR - PFS } \\
\hline LL & 135 & 58 & $77.41 \%$ & $61.67 \%$ & $51.93 \%$ & 93 & \multirow{3}{*}{$p=0.008$} \\
\hline $\mathrm{LH} / \mathrm{HL}$ & 43 & 22 & $65.29 \%$ & $45.42 \%$ & $41.93 \%$ & 26 & \\
\hline $\mathrm{HH}$ & 60 & 33 & $52.29 \%$ & $36.02 \%$ & $32.42 \%$ & 16 & \\
\hline
\end{tabular}

OS - overall survival; PFS — progression free survival; NLR — neutrophil/lymphocyte ratio; PLR — platelet/lymphocyte ratio
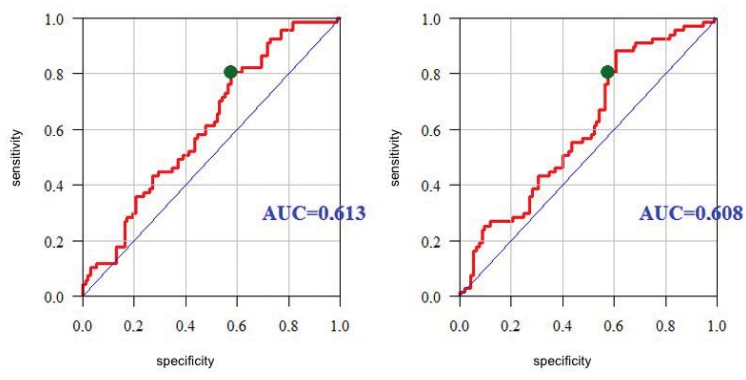

Figure 1. Kapplan-Meier overall survival and progression free survival curves for neutrophil/lymphocyte ratio (NLR)
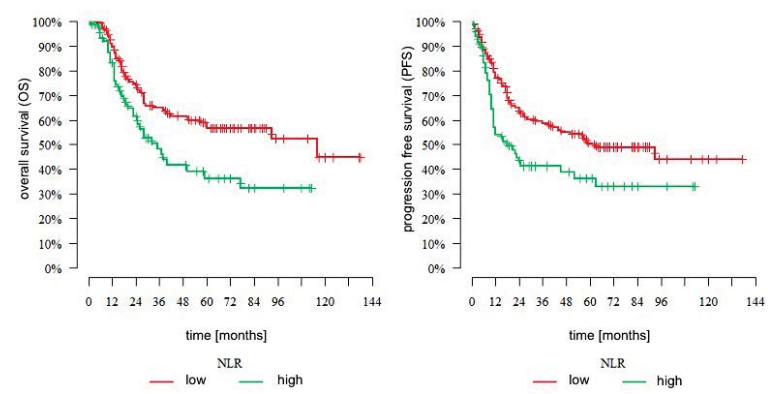

Figure 2. Receiver operating characteristic curves for neutrophil/ /lymphocyte ratio (NLR) (left) and platelet/lymphocyte ratio (PLR) (right); AUC — area under curve
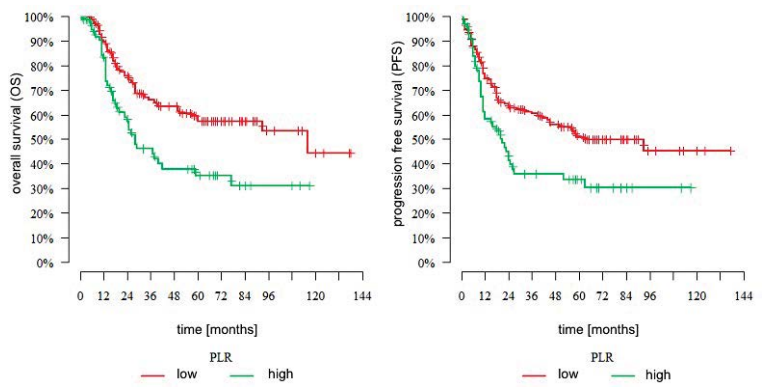

Figure 3. Kapplan-Meier overall survival and progression free survival curves for platelet/lymphocyte ratio (PLR)
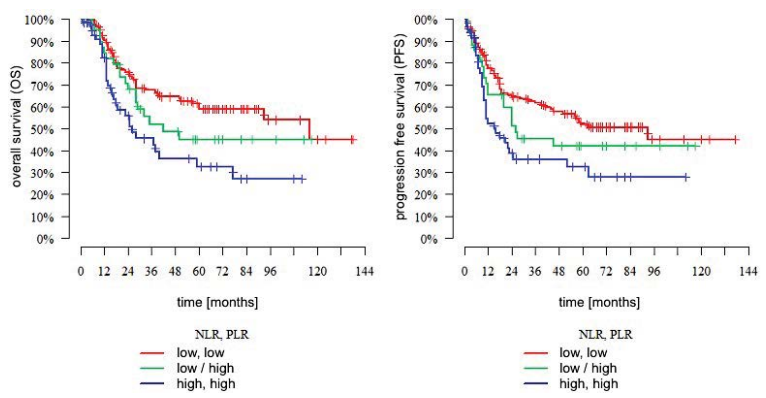

Figure 4. Kapplan-Meier overall survival and progression free survival curves for neutrophil/lymphocyte ratio (NLR)/platelet/lymphocyte ratio (PLR) $-\mathrm{L} / \mathrm{H}$. 


\begin{tabular}{|c|c|c|c|c|c|}
\hline \multicolumn{6}{|c|}{ Multivariate analysis including NLR } \\
\hline \multicolumn{2}{|l|}{ Feature } & HR & \multicolumn{2}{|l|}{$95 \% \mathrm{Cl}$} & p \\
\hline \multicolumn{6}{|l|}{ OS } \\
\hline Age & [years] & 1.03 & 0.998 & 1.062 & 0.064 \\
\hline \multirow{3}{*}{ Grade } & G1 & 1 & ref. & & \\
\hline & G2 & 1.012 & 0.364 & 2.815 & 0.982 \\
\hline & G3 & 1.634 & 0.544 & 4.912 & 0.382 \\
\hline \multirow{2}{*}{$\begin{array}{l}\text { Bokhman } \\
\text { type }\end{array}$} & 1 & 1 & ref. & & \\
\hline & $\|$ & 1.523 & 0.693 & 3.347 & 0.295 \\
\hline \multirow{2}{*}{ NLR } & Low & 1 & ref. & & \\
\hline & High & 2.589 & 1.281 & 5.235 & 0.008 \\
\hline \multicolumn{6}{|l|}{ PFS } \\
\hline Age & [years] & 1.026 & 0.997 & 1.057 & 0.084 \\
\hline \multirow{3}{*}{ Grade } & $\mathrm{Gl}$ & 1 & ref. & & \\
\hline & GII & 1.291 & 0.524 & 3.183 & 0.578 \\
\hline & GIII & 2.224 & 0.798 & 6.202 & 0.127 \\
\hline \multirow{2}{*}{$\begin{array}{l}\text { Bokhman } \\
\text { type }\end{array}$} & 1 & 1 & ref. & & \\
\hline & $\|$ & 1.661 & 0.796 & 3.467 & 0.177 \\
\hline \multirow{2}{*}{ NLR } & Low & 1 & ref. & & \\
\hline & High & 2.597 & 1.389 & 4.852 & 0.003 \\
\hline
\end{tabular}

OS - overall survival; PFS - progression free survival; $\mathrm{NLR}$ - neutrophil/lymphocyte ratio

values for NLR ranged from 3.0 to 5.0, the latter one being the most common (33\%). A marginally significant relation between cut-off values and hazard ratios was observed. There was a statistically significant correlation between NRL value and overall survival $(H R=1.81)$, which was also observed in relation to cancer specific survival (CSS), progression-free survival and disease-free survival (DFS). The strength of the correlation was bigger in cases of metastatic disease than in those confined to the primary tumour site. HR for metastatic cancer equalled 1.8 (1.63-1.99), and 1.57 (1.36-1.82) when there were no metastases. The authors explain that effect with bigger tumour burden or longer-lasting cancer-related inflammation in advanced cases [25].

The amount of papers on NLR in endometrial cancer is scarce. A meta-analysis conducted by Ethier on the prognostic value of NRL in gynaecological cancers includes only five studies concerning EC, three of which assessed only OS, and two where PFS was also taken into account. It has been noticed that in studies where five year survival was lower the NLR cut-offs tended to be set higher. No relation between most known clinic-pathologic prognostic factors and NLR was found, with the exception of histologic grade - G3. In cases of G3 endometrial cancer the correlation was stronger [21]. Haruma and al. made a retrospective analysis of 320 cases of EC. The study group was comprised of 253 FIGO stage
I-II patients and 67 FIGO stage III-IV patients. There were 276 cases of Bokhman type I EC (of which 40 were G3), and 46 type II. NLR and PLR measurements were taken in the month preceding surgery. NLR was found to be dependent on stage (FIGO I-II vs III-IV), histology (G1-2 vs G3 + type II EC) and myometrial invasion. Cut-off values were set as 2.7 for OS and 2.41 for DFS. In multivariate analysis only NLR and "histology" were determined to be independent prognostic factors [26]. Currently the biggest study concerning NRL in endometrial cancer was conducted by Cummings. It is a retrospective analysis of 733 EC patients in all stages, of which $78 \%$ were FIGOI-II. The authors examined the prognostic value of NLR, PLR and monocyte-lymphocyte ratio (MLR) measured before operative treatment. The optimal cut-off value for NLR was set to 2.4 in this study. A statistically significant correlation between NLR and OS as well as CSS was found in univariate analysis. In the multivariate analysis including variables such as age, stage, grade, Bokhman type and LVSI invasion, NLR was determined to be an independent prognostic factor [15].

As opposed to the above-mentioned papers, this study is focused solely on the advanced EC patients - FIGO stages III-IV, and the NRL and PLR values have not been measured before surgery but at the stage of adjuvant treatment planning. The results of the univariate analysis indicate a statistically significant correlation between the value of NLR and 5-year OS - HR = $1.06(p<0.001)$ and PFS - HR $=1.054(p<0.001)$. The mean NLR value in the study group was 4.2 [standard deviation (SD) 6.43], and its median 3.13. An optimal cut-off value of 3.88 has been set using the ROC curve analysis. Five year overall survival was $57 \%$ and $36 \%$ for low and high NLR accordingly. No relation between NLR and Bokhman type, histologic grade or surgical radicality was found. The results of a multivariate analysis including age, histologic grade and Bokhman type have shown that NLR is the only independent prognostic factor of OS (HR = 2.6), as well as of PFS (HR = 2.6) in this study group. Hazard ratio values obtained in the univariate analysis are lower than in the cited papers which may be due to a smaller tumour burden after surgery, that may implicate a weaker cancer-related immune response. Such an explanation was suggested in the Templeton meta-analysis. It is important to notice that the set NLR cut-off value (3.88) was considerably different than those in Cummings and Haruma studies $(2.4,2.7)$, and were closer to those observed by Templeton in cases of advanced or metastatic cancer (4-5).

Platelets take part in the tumour promoting inflammatory response. One of the essential elements of the process is II-6 which promotes megakaryocyte differentiation into platelets by stimulating the production of thrombopoietin. High level of II- 6 was proven to be an independent prognos- 
tic factor of bad outcome in ovarian cancer. Its reflection in $\mathrm{CBC}$ might be high platelet count. PLR is a parameter derived from $C B C$, which takes into account the platelet count as well as the lymphocyte count $[5,22,23]$.

One of the most comprehensive studies on the prognostic value of PLR in solid tumours is a 2014 meta-analysis conducted by Templeton. It includes 12,890 patients from 22 different studies, who were diagnosed with such malignancies as mesothelioma, pancreatic, breast or ovarian cancer among others. It does not include any studies concerning endometrial cancer. The authors point out that a significant prognostic value of PLR is observed especially with advanced cancer. In studies where the disease was confined to the primary site the effect was rarely seen or marginal. The determined optimal cut-off values ranged from 150 to 300 depending on the type of cancer and its stage, and in most cases were higher in the metastatic disease. The authors conclude that the prognostic value of PLR is strongly dependent on the stage of cancer, and it tends to be higher in more advanced stages [24].

The number of papers regarding PLR in EC is scant. The Haruma study quoted before is one of the two major studies relating to PLR in endometrial cancer. The results indicate that similarly to NLR also PLR was influenced by stage , ,histology" and depth of myometrial invasion. The prognostic value of PLR was proven to be statistically significant in terms of OS and DFS only in the univariate analysis. The determined cut-off value was 175 . The authors conclude that PLR is a weaker prognostic factor than NLR [26]. The second of the major studies, by Cummings, was also referred to previously in the context of NLR. The cut-off value set by the authors for PLR was 240. The results of the univariate analysis have shown a significant correlation between PRL and OS as well as CSS. The outcome of multivariate analysis, which included age, stage, histologic grade, Bokhman type, and LVSI status indicated PLR as an independent prognostic factor. It was also shown that the value of PRL is related significantly to age, stage, nodal involvement and LVSI status. The authors have distinguished three prognostic groups based on the PLR and NLR values, which differed in OS and CSS in a statistically significant way [15].

The results of Cox proportional hazard analysis in our group of aEC patients indicate that the correlation between PLR and 5-year OS (HR = 1.001; $p=0.011)$ and PFS $(H R=1.001 ; p=0.011)$ is statistically significant in the univariate analysis. The hazard ratio value is low because of the small unitary value of the parameter - the mean value was 237 , and the standard deviation was 178 in the study group. The determined optimal cut-off value was 231.3 (sensitivity $80.6 \%$; specificity $42.4 \%)$. When dichotomised, the parameter allowed the formation of two groups differing significantly in terms of 5-year OS ( $\mathrm{L}-57.4 \%$; $\mathrm{H}-35.4 \%)$ and PFS ( $L-50.9 \% ; \mathrm{H}-33.6 \%)$. Similarly to NLR there was no significant relation between PLR and histologic type, grade and surgical radicality. The outcome of a multivariate analysis indicated that PLR is not an independent prognostic factor of neither OS nor PFS in aEC. The cut-off values which were defined as optimal in our analysis were similar to those in the paper by Cummings et al.

What has to be pointed out is that due to the low specificity of the dichotomised NLR and PLR some patients might be misclassified, so the cut-off values should be reassessed in a better designed, preferably prospective study.

The outcome of stratification of our group of aEC patients to three risk groups, based on the NLR and PLR status met our expectations. The 5-year OS in the low-risk group was $59 \%$ in comparison to $33 \%$ in the high-risk group. The differences were statistically significant. The proposed division may provide an additional argument in the decision-making process while planning individual adjuvant treatment for advanced endometrial cancer patients.

\section{CONCLUSIONS}

Both NLR and PLR measured before adjuvant treatment were found to have significant prognostic value in relation to OS and PFS among advanced endometrial cancer patients, while in the multivariate analysis NLR was found to be an independent prognostic factor of OS as well as PFS. Taking into account the fact that the determination of those parameters is cost neutral, they may be easily taken into consideration in the decision-making process while planning individualised adjuvant treatment for aEC patients. Further prospective studies should be carried out for better determination of their prognostic value and optimal cut-off points in aEC.

\section{Conflict of interest}

The authors declare no conflict of interest.

\section{Funding}

The study was financed from authors own funds.

\section{REFERENCES}

1. GLOBOCAN 2018, Cancer Incidence Mortality and Prevalence Worldwide 2018. http://gco.iarc.fr/today.

2. KRN - Krajowy Rejestr Nowotworów. http://onkologia.org.pl.

3. Wojciechowska U, Czaderny K, Ciuba A, Olasek P, Didkowska J. Nowotwory złośliwe w Polsce w 2016 roku. Centrum Onkologii Instytut im. M. Skłodowskiej-Curie, Warszawa 2018.

4. Balkwill F, Mantovani A. Inflammation and cancer: back to Virchow? Lancet. 2001;357(9255):539-545, doi: 10.1016/S0140-6736(00)04046-0, indexed in Pubmed: 11229684.

5. Balkwill F, Charles KA, Mantovani A. Smoldering and polarized inflammation in the initiation and promotion of malignant disease. Cancer Cell. 2005; 7(3): 211-217, doi: 10.1016/j.ccr.2005.02.013, indexed in Pubmed: 15766659.

6. Coussens LM, Werb Z. Inflammation and cancer. Nature. 2002; 420(6917): 860-867, doi: 10.1038/nature01322, indexed in Pubmed: 12490959. 
7. Petrie HT, Klassen LW, Kay HD. Inhibition of human cytotoxic T lymphocyte activity in vitro by autologous peripheral blood granulocytes. J Immunol. 1985; 134(1): 230-234, indexed in Pubmed: 3871101.

8. De Larco JE, Wuertz BRK, Furcht LT. The potential role of neutrophils in promoting the metastatic phenotype of tumors releasing interleukin-8. Clin Cancer Res. 2004; 10(15): 4895-4900, doi: 10.1158/1078-0432.CCR03-0760, indexed in Pubmed: 15297389.

9. Mantovani A, Allavena P, Sica A, et al. Cancer-related inflammation. Nature. 2008; 454(7203): 436-444, doi: 10.1038/nature07205, indexed in Pubmed: 18650914.

10. Granot Z, Jablonska J. Distinct Functions of Neutrophil in Cancer and Its Regulation. Mediators Inflamm. 2015; 2015: 701067, doi: 10.1155/2015/701067, indexed in Pubmed: 26648665.

11. Uribe-Querol E, Rosales C. Neutrophils in Cancer:Two Sides of the Same Coin. J Immunol Res. 2015; 2015: 983698, doi: 10.1155/2015/983698, indexed in Pubmed: 26819959.

12. Thavaramara T, Phaloprakarn C, Tangjitgamol S, et al. Role of neutrophil to lymphocyte ratio as a prognostic indicator for epithelial ovarian cancer. J Med Assoc Thai. 2011; 94(7): 871-877, indexed in Pubmed: 21774296.

13. Raungkaewmanee $S$, Tangjitgamol S, Manusirivithaya $S$, et al. Platelet to lymphocyte ratio as a prognostic factor for epithelial ovarian cancer. J Gynecol Oncol. 2012; 23(4): 265-273, doi: 10.3802/jgo.2012.23.4.265, indexed in Pubmed: 23094130.

14. Ural ÜM, Şehitoğlu İ, Tekin YB, et al. Neutrophil-to-lymphocyte and platelet-to-lymphocyte ratios in patients with endometrial hyperplasia and endometrial cancer. Obstet Gynaecol Res. 2014; 41(3): 445-448, doi: $10.1111 /$ jog. 12536 .

15. Cummings $M$, Merone $L$, Keeble $C$, et al. Preoperative neutrophil: lymphocyte and platelet:lymphocyte ratios predict endometrial cancer survival. Br J Cancer. 2015; 113(2): 311-320, doi: 10.1038/bjc.2015.200, indexed in Pubmed: 26079303.

16. Gooden MJM, de Bock GH, Leffers N, et al. The prognostic influence of tumour-infiltrating lymphocytes in cancer: a systematic review with meta-analysis. Br J Cancer. 2011; 105(1): 93-103, doi: 10.1038/bjc.2011.189, indexed in Pubmed: 21629244.
17. Petrie HT, Klassen LW, Kay HD. Inhibition of human cytotoxic T lymphocyte activity in vitro by autologous peripheral blood granulocytes. J Immunol. 1985; 134(1): 230-234, indexed in Pubmed: 3871101.

18. McCourt M, Wang JH, Sookhai S, et al. Proinflammatory mediators stimulate neutrophil-directed angiogenesis. Arch Surg. 1999; 134(12): 1325-31; discussion 1331, doi: 10.1001/archsurg.134.12.1325, indexed in Pubmed: 10593330.

19. Di Carlo E, Forni G, Musiani P. Neutrophils in the antitumoral immune response. Chem Immunol Allergy. 2003; 83: 182-203, doi: 10.1159/000071561, indexed in Pubmed: 12947985.

20. Templeton AJ, McNamara MG, Šeruga $B$, et al. Prognostic role of neutrophil-to-lymphocyte ratio in solid tumors: a systematic review and meta-analysis. J Natl Cancer Inst. 2014; 106(6): dju124, doi: 10.1093/jnci/dju124, indexed in Pubmed: 24875653.

21. Ethier JL, Desautels DN, Templeton AJ, et al. Is the neutrophil-to-lymphocyte ratio prognostic of survival outcomes in gynecologic cancers? A systematic review and meta-analysis. Gynecol Oncol. 2017; 145(3): 584-594, doi: 10.1016/j.ygyno.2017.02.026, indexed in Pubmed: 28222899.

22. Imai T, Koike K, Kubo T, et al. Interleukin-6 supports human megakaryocytic proliferation and differentiation in vitro. Blood. 1991; 78(8): 1969-1974, indexed in Pubmed: 1912578.

23. Lippitz BE. Cytokine patterns in patients with cancer: a systematic review. LancetOncol.2013;14(6):e218-e228, doi:10.1016/S1470-2045(12)70582-X, indexed in Pubmed: 23639322

24. Templeton AJ, Ace O, McNamara MG, et al. Prognostic role of platelet to lymphocyte ratio in solid tumors: a systematic review and meta-analysis. Cancer Epidemiol Biomarkers Prev. 2014; 23(7): 1204-1212, doi: 10.1158/1055-9965.EPI-14-0146, indexed in Pubmed: 24793958.

25. Aggarwal BB, Vijayalekshmi RV, Sung B. Targeting inflammatory pathways for prevention and therapy of cancer: short-term friend, long-term foe. Clin Cancer Res. 2009; 15(2): 425-430, doi: 10.1158/1078-0432. CCR-08-0149, indexed in Pubmed: 19147746.

26. Haruma T, Nakamura K, Nishida T, et al. Pre-treatment neutrophil to lymphocyte ratio is a predictor of prognosis in endometrial cancer. Anticancer Res. 2015; 35(1): 337-343, indexed in Pubmed: 25550569. 